\title{
Effects of thermal treatment on the characteristics quality of some Ghanaian vegetable oils (palm, coconut and groundnut)
}

Robert A Ngala ( $\square$ rngala2000@yahoo.com )

Kwame Nkrumah University of Science and Technology Kumasi

Evans Owusu Ameyaw

Kwame Nkrumah University of Science and Technology Kumasi

Dorice Berkoh

Kwame Nkrumah University of Science and Technology Kumasi

John Barimah

Kwame Nkrumah University of Science and Technology Kumasi

Simon Koffie

Kwame Nkrumah University of Science and Technology Kumasi

\section{Research Article}

Keywords: Vegetable oils, Thermal treatment, Diabetes Mellitus, antioxidant

Posted Date: January 13th, 2022

DOI: https://doi.org/10.21203/rs.3.rs-537131/v2

License: (9) This work is licensed under a Creative Commons Attribution 4.0 International License. Read Full License 
1 Effects of thermal treatment on the characteristics quality of some Ghanaian vegetable oils

2 (palm, coconut and groundnut)

3 ' ${ }^{2}$ Evans Owusu Ameyaw, ${ }^{1}$ Dorice A Berkoh, ${ }^{1}$ Simon Koffie, ${ }^{2}$ John Barimah. ${ }^{1}$ Robert A $4 \quad$ Ngala

5

6 Corresponding Author

$7 \quad$ Robert A Ngala

$8 \quad{ }^{1}$ Department of Molecular Medicine

9 SMD

10 Kwame Nkrumah University of Science and Technology Kumasi Ghana

11 E-mail rngala2000@yahoo.com

$12 \quad{ }^{2}$ Kwame Nkrumah University of Science and Technology Kumasi Ghana

13 Department of Food and Biotechnonlogy

\section{Abstract}

18 Introduction: Vegetable oils contain natural antioxidants and other properties reported to impart 19 anti-diabetic properties when consumed, in animal study. In humans however, these oils are 20 subjected to high temperatures during cooking before consumption. High temperature tends to 21 affect the characteristic quality and potential to impart on health benefits such as antidiabetic

22 properties. The objective of this work was to determine the characteristics quality of vegetable 
23 oils after thermal treatment that equates to temperatures oils are subjected to during food 24 processing/cooking.

25 Methodology: Three portions of $200 \mathrm{~g}$ of each fresh unrefined red palm oil, coconut oil and 26 groundnut oils in three conical flasks T1, T2 and T3 were heated to room temperature $28^{\circ} \mathrm{C}(\mathrm{T} 1)$

27 to $100^{\circ} \mathrm{C}$ in boiling water (T2) and to $200^{\circ} \mathrm{C}$ in electric cooker oven (T3) for 10 minutes. Acid, 28 iodine, peroxide, saponification, unsaponification values of the oils, Phytoconstituents 29 (Flavonoids, polyphenols saponins etc.), Total antioxidant capacity and DPPH (1,1-Diphenyl-230 Picrylhydrazyl) Radical Scavenging Activity were then determined after cooling to room 31 temperature.

32 Results; Coconut oil heated to $200^{\circ} \mathrm{C}$ had the least Acid value of $2.89 \pm 0.135$ whiles Palm oil 33 heated to $100{ }^{\circ} \mathrm{C}$ had the highest value of $19.57 \pm 0.165$. There were no peroxides formed in 34 Coconut and Palm oils at $28{ }^{\circ} \mathrm{C}$ as well as Palm oil at $100{ }^{\circ} \mathrm{C}$. However, peroxides were highest 35 in Coconut oil at $200^{\circ} \mathrm{C}$ with value of $15.28 \pm 2.315$. Saponification value of groundnut oil at 28 $36{ }^{\circ} \mathrm{C}$ was the least at $89.52 \pm 2.18$ and $296.57 \pm 1.045$ the highest in coconut oil at $200{ }^{\circ} \mathrm{C}$. Heating 37 however increased the unsaponifiable matter in all the vegetable oils used. Phenolic constituents 38 were significantly increased in palm oil at higher temperatures and only significantly increased at $39100^{\mathrm{C}}$ for coconut and groundnut oils. Total antioxidant capacity was not significantly changed in 40 all the oils at higher temperature. Free radical scavenging activity was not significantly changed 41 at higher temperature in all the oils

42

\section{Conclusion}

44 The quality of the oils in terms of acid value, iodine vale, peroxide value and saponification 45 value, total antioxidant and phenolic content were retained after one heat treatment. This implies 
46 the quality of the oils are maintained after a single heating. The oils may still retain antidiabetic

47 property when consumed after processing.

$49 \quad$ Key Words

50 Vegetable oils, Thermal treatment, Diabetes Mellitus, antioxidant

\section{$51 \quad$ Introduction}

52 Vegetable oils are triglycerides extracted from plants and termed as plant oils that are mostly 53 liquid at room temperature or fat when solid [1]. Vegetable oils are used for many purposes, 54 mostly for cooking, as fuels, paints, and in skin care product and other pharmaceutical products $55[2-3-4]$.

56 Medical benefits from the consumption of vegetable oils are conflicting. Consumption of some 57 of these oils have been associated with the induction of cardiovascular diseases due to their 58 atherogenic effect because they contain high amounts of omega-6 fats and excessive 59 consumption of omega-6s can create chronic inflammatory reactions [5] which is associated 60 with the development of atherosclerosis [6- 7], particularly the long chain and saturated fatty 61 acids [8 ]. Other researchers have found that linoleic acid-rich vegetable oil in place of saturated 62 fat, produced no evidence for reductions in either coronary heart disease mortality or all-cause

63 mortality [9]. A positive association after consumption of some oils have been observed in 64 cardiovascular disease (CVD) and type 2 diabetes mellitus (DM). Consumption of olive oil was 65 inversely associated with serum cholesterol and glucose levels and systolic blood pressure [10]]. 66 Ngala et al showed that $10 \%$ by weight vegetable oil: coconut oil, groundnut oil and red palm oil 
67 added to rodent chaw significantly reduced blood glucose level in diabetic mice and showed no 68 dyslipidaemic effect [11].

69 Red palm oil is an edible vegetable oil derived from the mesocarp (reddish pulp) of the fruit of 70 the oil palm, primarily the African oil palm (Elaeis guineensis,) [12]. Red palm oil is rich in 71 carotenes, such as alpha-carotene, beta-carotene and lycopene, which give it a characteristic dark 72 red color $[13,14]$. Palm oil is mainly composed of fatty acids, esterified with glycerol. It has a 73 high concentration of saturated fat; palmitic acid and oleic acid which is monounsaturated. 74 Unrefined palm oil is a significant source of tocotrienol, part of the vitamin E family [12]. 75 Coconut oil or copra oil is obtained from the dried kernel of coconut [15]. Coconut (Cocos 76 nucifera) oil contains medium chain fatty acids, basically comprises of lauric acid (47.5\%) which 77 is reported to be a better alternative to other saturated fatty acids. Groundnut or Peanut oil, is a 78 mild-tasting vegetable oil derived from groundnut (arachis hypogeal) [16]. Its major component 79 fatty acids include oleic acid (46.8\% as olein), linoleic acid (33.4\% as linolein), and palmitic acid 80 (10.0\% as palmitin). The oil also contains some stearic acid, arachidic acid, behenic acid, 81 lignoceric acid and other fatty acids [17]. It is believed that the antioxidant carotenes, 82 unsaturation and short chain fatty acids confer the oils their antidiabetic effect [11].

83 However, the antidiabetic properties of vegetable oil may be deteriorated by thermal effect 84 during food processing that leads to lipid oxidation. Prolonged consumption of repeatedly heated 85 oil has been shown to increase blood pressure and total cholesterol, cause vascular inflammation 86 and vascular changes which predisposes to atherosclerosis as a result of lipid peroxidation [1887 19]. 
88 This work is a follow up of our earlier publication Ngala et al 2016 [11]. In this work 10\%

89 vegetable oils, groundnut oil, coconut oil and red palm oil reduced blood glucose in diabetic

90 mice and had no dyslipideamic effect. Currently we are studying the effect of these oils in

91 diabetic humans. However, humans do not consume these oils only at room temperature as was

92 used in the mice study. In food processing varying temperatures are used, hence the need to

93 determine whether these processing temperatures would have an effect on the quality of the oils,

94 and whether the oils will maintain their antidiabetic properties after processing.

95 This work therefore involves determining the quality of the vegetable oils after a single heating 96 at different food processing/cooking temperatures.

\section{Methods}

98 The protocol for this study was approved by the Health Service Ethics Committee, School of

99 Medicine and Dentistry, Kwame Nkrumah University of Science and Technology Kumasi,

100 Ghana

101 Fresh unrefined palm was supplied by Benso Oil Plantation Ltd, coconut and groundnut oils 102 were bought from the Ghana Food Distribution Corporation. These Food processing Companies 103 are licensed by the Ghana Standard Authority. The Ghana Standard Authority certified the oils to 104 be of good grade and gave approval for their use. Two hundred grams (200g) of each of the oils 105 were placed in three conical flasks T1 T2 and T3. All the oils in T1 flasks were maintained at 106 room temperature $\left(28^{0} \mathrm{C}\right)$ whilst those in $\mathrm{T} 2$ and $\mathrm{T} 3$ flasks were heated in water bath and electric 107 oven to $100^{\circ} \mathrm{C}$ and $200^{\circ} \mathrm{C}$ respectively for 10 minutes and analysis were then made on the three 108 different oils in their three different temperature treatments after cooling to room temperature 109 using methods from AOAC (1990) [20]. 


\section{Acid Value Determination}

111 Five grams $(5 \mathrm{~g})$ of each of the oil treated at T1, T2 and T3 were weighed into a 250ml conical 112 flask. $100 \mathrm{ml}$ of freshly neutralized ethanol and $1 \mathrm{ml}$ of phenolphthalein indicator were added to 113 each of the oil samples. The mixtures were then boiled for $5 \mathrm{~min}$ and titrated against a $1 \mathrm{M}$ sodium

114 hydroxide solution. The acid value was then calculated using the formula

115 Acid Value $=\frac{56.1 \mathrm{~N}}{\mathrm{~W}}$ where $(\mathrm{V}=$ vol. of $\mathrm{NaOH}$ used, $\mathrm{N}=$ Normality of $\mathrm{NaOH}$ and $\mathrm{W}=$ wt. of

\section{Iodine Value Determination}

117 To determine the iodine value, $0.5 \mathrm{~g}$ of treated oil samples were weighed into 2 separate $500 \mathrm{ml}$ 118 glass-stopped flasks. Afterwards, $10 \mathrm{ml}$ of chloroform was added to each sample to dissolve the 119 oils whiles two blanks were prepared by adding only $10 \mathrm{ml}$ of the chloroform into the $500 \mathrm{ml}$ 120 glass-stopped flasks. 25ml of Wij's solution was then added to each flask and swirled gently to $121 \mathrm{mix}$ and incubated in the dark for $30 \mathrm{~min}$. After the incubation, $20 \mathrm{ml}$ of $(1 \mathrm{M})$ potassium iodide 122 solution was added to each flask, followed by washing down of any free iodine on the stopper 123 with a $100 \mathrm{ml}$ freshly boiled and cooled water. The liberated iodine in the flasks was then titrated 124 with $0.1 \mathrm{~N}$ sodium thiosulphate solution, adding it gradually with vigorous shaking until the 125 yellow color almost disappeared. $1 \mathrm{ml}$ of starch indicator was then added while continuing the 126 titration until the blue color disappeared entirely. The volume of the titrant was then recorded 127 and the iodine value was calculated from it using the formula:

128 Iodine Value $=\frac{(B-S) * N * 126.9}{\mathrm{~W}} * 100$ 
129 (Where $\mathrm{B}=$ vol. of titrant for blank, $\mathrm{N}=$ normality of $\mathrm{Na}_{2} \mathrm{SO}_{3}, \mathrm{~S}=$ vol. of titrant for sample,

$130126.9=\mathrm{MW}$. Of Iodine, $\mathrm{W}=$ weight of sample)

\section{Peroxide value determination}

132 Five grams $(5 \mathrm{~g})$ of each of the treated oils was weighed into two $250 \mathrm{ml}$ glass-stopped 133 erlenmeyer flasks respectively. $30 \mathrm{ml}$ of acetic acid-chloroform solution (3:2) was added to each 134 flask and swirled to dissolve. $0.5 \mathrm{ml}$ saturated $\mathrm{KI}$ solution and $30 \mathrm{ml}$ distilled water were then 135 added, the samples were then titrated slowly with $0.1 \mathrm{~N}$ sodium thiosulphate solution with 136 vigorous shaking until yellow color almost disappeared. $0.5 \mathrm{ml}$ of starch indicator was then added 137 while continuing the titration to liberate all iodine from the chloroform layer until the blue color 138 disappeared entirely. The procedure was then repeated using a blank without oil as the control, 139 the volume of the titrant was recorded and used to calculate for the peroxide value from the 140 formula:

141 peroxide value $=\frac{(S-B) * N}{\mathrm{w}} * 1000$

142 (where $\mathrm{B}=$ vol. of titrant for blank, $\mathrm{N}=$ normality of $\mathrm{NA}_{2} \mathrm{SO}_{3}, \mathrm{~S}=$ vol. of titrant for sample, $143 \quad 126.9=$ mw. of iodine, $w=$ weight of sample)

\section{Saponification Value Determination}

145 The saponification values of the vegetable oils were determined by weighing $1.5 \mathrm{~g}$ each of treated 146 oils into two $250 \mathrm{ml}$ Erlenmeyer flasks. $25 \mathrm{ml}$ of alcoholic $\mathrm{KOH}$ solution was pipetted into each

147 flask including a blank. The sample and the blank flasks were connected to air condensers and 148 kept in a water bath boiling gently. Saponification was completed when the oily solution was 
149 clear. After cooling, the condenser was washed down with 10ml ethanol. Excess KOH was then

150 titrated with $0.5 \mathrm{~N}$ HCL using $1 \mathrm{ml}$ phenolphthalein as indicator. Using the titrant obtained, the

151 saponification values calculated obtained using the formula:

152 Saponification Value $=\frac{56.1(B-S) * N}{\mathrm{~W}}$

153 (Where $\mathrm{B}=$ vol. of HCL for blank, $\mathrm{N}=$ normality of standard HCL, $\mathrm{S}=$ vol. of HCL for sample,

$154 \mathrm{~W}=$ weight of oil sample)

155 Unsaponification Value Determination

156 The unsaponification values of the treated oils were determined by weighing $5 \mathrm{~g}$ each of the 157 respective treated oils into $250 \mathrm{ml}$ Erlenmeyer flasks. $50 \mathrm{ml}$ of alcoholic $\mathrm{KOH}$ solution was 158 pipetted into each flask. The flasks were then connected to an air condenser and boiled for an 159 hour to complete the saponification process. The condenser was then washed with $10 \mathrm{ml}$ ethanol. 160 The saponified mixture was then transferred into a separating funnel, rinsed with water and 161 cooled. $50 \mathrm{ml}$ of petroleum ether was then added to each flask and mixed. The lower soap layer 162 was then transferred into another separating funnel and the process repeated three times to get 163 maximum extraction. The ether extract was then washed 3 times with $25 \mathrm{ml}$ portions of aqueous 164 alcohol followed by $25 \mathrm{ml}$ portions of distilled water to ensure that the ether extracts are free 165 from alkali. The ether solution was transferred into a $250 \mathrm{ml}$ beaker and all ether evaporated into 166 a flask. While heating on a water bath, $2 \mathrm{ml}$ of acetone was added to remove solvents completely. 167 The last traces of ether were removed by drying at $100^{\circ} \mathrm{C}$ for $30 \mathrm{~min}$ till constant weight was 168 obtained. The residues were then dissolved in $50 \mathrm{ml}$ warm ethanol neutralized to a 169 phenolphthalein endpoint. The solutions obtained were then titrated with $0.02 \mathrm{~N}$ sodium 
170 hydroxide solution. The titrant obtained was used to calculate for the unsaponification value of

171 each sample using the formula: $\frac{100(A-B)}{\mathrm{W}}$

172 (Where, $\mathrm{A}=$ wt. of residue, $\mathrm{B}=$ wt. of FFA in the extract, $\mathrm{W}=$ weight of the sample)

173 Antioxidant Activity Assays.

1. DPPH (1,1-diphenyl-2-picrylhydrazyl) free radical scavenging assay.

175 The free radical scavenging activity was determined as described by Gorinstein et al. [21] with 176 modifications. $1 \mathrm{ml}$ each of the different concentrations $(500-15.625 \mu \mathrm{g} / \mathrm{mL})$ of the extracted 177 oil was added to $3 \mathrm{ml}$ methanol solution of DPPH $(20 \mathrm{mg} / \mathrm{l})$ in test tubes. The reaction mixture 178 was kept at $25^{\circ} \mathrm{C}$ in the dark for 30 minutes. The process was repeated for ascorbic acid (100 $1791.56250 \mu \mathrm{g} / \mathrm{mL}$ ) of different concentrations. The absorbance of the residual DPPH was 180 determined at $517 \mathrm{~nm}$ in a Multimode Microplate reader. The DPPH radical scavenging activity 181 was calculated according to the following equation:

$182 \%$ DPPH radical scavenging activity $=\left(1-\left(\frac{\text { Abs of sample }}{\text { Abs of control }}\right)\right) \times 100 \%$

183 and the \% DPPH radical scavenging activity was plotted against the log concentration of the 184 standard and extracts. The concentration of the extracts and standard required to scavenge $50 \%$ 185 of DPPH was expressed as $\mathrm{IC}_{50}$.

187 The assay is based on the reduction of molybdenum, $\mathrm{Mo}^{6+}$ to $\mathrm{Mo}^{5+}$ by the oil extracts and 188 subsequent formation of a green phosphate-molybdate $\left(\mathrm{Mo}^{5+}\right)$ complex at acidic $\mathrm{pH}$. The reagent 189 solution was prepared by the addition of Ammonium molybdate $(4 \mathrm{mM})$, disodium hydrogen 190 phosphate $(28 \mathrm{mM})$ and sulphuric acid $(6 \mathrm{mM}) .1 \mathrm{ml}$ each of different concentrations $(1000-$ $19131.25 \mu \mathrm{g} / \mathrm{mL}$ ) of the extract was measured into test tubes. $3 \mathrm{ml}$ of the reagent solution added to 
192 each and incubated at $95^{\circ} \mathrm{C}$ for 90 mins. The ascorbic acid $(200-1.5625 \mu \mathrm{g} / \mathrm{mL})$ solutions were

193 also taken through the same procedure and absorbance measured at $695 \mathrm{~nm}$ using the multimode

194 microplate reader. The antioxidant capacity was expressed as mg of ascorbic acid equivalent

195 (AAE) per $g$ of extract [22]

\section{Total Phenol Content (Folin Ciocalteau assay)}

197 Each of the various solutions $(1000-31.25 \mu \mathrm{g} / \mathrm{mL})$ of the oil extracts $(0.5 \mathrm{ml})$ were measured 198 into test tubes and $2.5 \mathrm{ml}$ of the Folin-Ciocalteau reagent added to each. Two milliliters of the 199 aqueous sodium carbonate solutions $(75 \mathrm{mg} / \mathrm{ml})$ were added to each and stored in the oven at $20050^{\circ} \mathrm{C}$ for $10 \mathrm{mins}$ and the absorbances read at $760 \mathrm{~nm}$ using a multi-mode microplate reader. The 201 gallic acid solutions $(50-1.5625 \mu \mathrm{g} / \mathrm{mL})$ was taken through the same procedure and used to plot 202 a calibration curve. The phenolic content was expressed in gallic acid equivalents (mg GAE/ g 203 extract) [23] with some modifications.

207 Normality of data was checked using the KolmogorovSmirnov test. The data analysis was done 208 using Graph Pad Prism version 8.00 for windows (GraphPad Software, San Diego California, 209 USA). Baseline characteristics were expressed as mean \pm standard error of means (SEM). One210 way analysis of variance (ANOVA) with Dunnett's test was used for multiple comparisons 211 between the oil groups. $\mathrm{P} \leq$ value $<0.05$ was considered significant. 


\section{Results and Discussion}

218 Acid Value

219 Table 1.0

220 Table 1 depicts palm oil had the highest acid value, whilst coconut had the least acid value

221 between the oils. There were no statistically significant changes in the acid values in the 222 individual oils at different temperature treatment (room temperature $100^{\circ} \mathrm{C}$ and $200^{\circ} \mathrm{C}$ ).

223 The acid value represents the degree of degradation of the oil quality resulting from hydrolysis of 224 triacylglycerols of the oils as a result of temperature and moisture on lypolytic enzyme lipase $225[24,25]$. It has been well-established that heating of dietary oils and fats results in oxidation, hydrolysis, 226 polymerisation and isomerisation. Heating oil elevate the percentage of peroxide value by 8 -fold, free 227 fatty acid value by 15 -fold, acid value by 14 -fold, trans fatty acid isomer value (2.5-fold), $p$-anisidine 228 value (39-fold), total oxidation value (19-fold), and thiobarbituric acid reactive substance (TBARS) value 229 (8.5-fold) compared to the control [26].

230 The reactions are deleterious to the stability of fatty acids and other biochemical parameters of the oil [27231 28]. Furthermore, vitamin E, which is a natural antioxidant, in the oil also deteriorates after repeated 232 heating [29]. In most food processing, particularly deep frying may heat oils to above $180^{\circ} \mathrm{C}$. 
233 From this study, first time thermal treatment of oil up to $200^{\circ} \mathrm{C}$ did not significantly destroy the

234 acid value of the oils. Similar finding was also recorded by Jaarin and Kamisiah in which single

235 heating of palm and soya oils at $200^{\circ} \mathrm{C}$ did not affect the acid composition of the oils [30].

\section{Iodine Value}

Table 2.0

241 There were no significant changes in the iodine (IV) values of the individual oils after thermal

242 treatment (Table 2.0). However, in between the oils the iodine values were significantly higher 243 in the groundnut oil, followed by palm oil after each thermal treatment. This implies there are 244 more unsaturated bonds in groundnut oil compared to palm oil and coconut oil, and coconut oil 245 had the least unsaturation.

246 The Iodine value (IV) is a measure of the degree of unsaturation in the oils and determines the

247 vulnerability of the oil to oxidation. The higher the iodine value, the more susceptible the oil is to 248 oxidation [25].

249 Heating of the various oils (Palm, Coconut and Groundnut oils) up to $200^{\circ} \mathrm{C}$ had no significant 250 effect $(\mathrm{p}>0.05)$ on the iodine values compared to the values of the unheated oils. This was 251 similar to a work reported by Gharby et al. [31], in which heat applied to Virgin Olive oil had no 252 significant effect $(\mathrm{p}>0.05)$ in the iodine values of the oil. This implies no change in the degree 253 of unsaturation of the oil after the thermal treatment, and the oils may not be further susceptible 254 to peroxidation as was observed in the acid values. 


\section{3.0 Peroxide Value}

256 The peroxides formed within the various oils (Palm, Coconut and Groundnut) at different

257 temperatures are represented in Table 3.

258 Table 3.

259

260 The peroxide value can be defined as the amount of peroxide oxygen per 1 kilogram of fat or oil 261 according to Kaleem et al [32]. Oil with peroxide value between 1 and 5 meqO $/ \mathrm{kg}$ is classified 262 as low oxidation state and that between 5 and $10 \mathrm{meq} \mathrm{O}_{2} / \mathrm{kg}$ as moderate oxidation and above 10 263 meq $\mathrm{O}_{2} / \mathrm{kg}$ classified as high oxidation state [33].

264 Oxidative reactions of the oils can be affected by heat [34-35], oils with a higher degree of 265 unsaturation are highly susceptible to autoxidation and hence the best test for autoxidation 266 (oxidative rancidity) is the determination of the peroxide value (PV), because peroxides are 267 intermediates in the autoxidation reaction [36].

268 There were no peroxides in palm oil at room temperature and at a $100^{\circ} \mathrm{C}$ heating but very low 269 oxidation $\left(6.63 \mathrm{meq} \mathrm{O}_{2} / \mathrm{kg}\right)$ at $200^{\circ} \mathrm{C}$. At room temperature coconut oil similarly had no peroxide 270 value but trace amount at $100^{\circ} \mathrm{C}$ and a very significant quantity at $200^{\circ} \mathrm{C}$. Groundnut oil on the 271 other hand showed comparatively significant number of peroxides at room temperature $8.77 \pm$ $2720.100 \mathrm{meq} \mathrm{O}_{2} / \mathrm{kg}$ and significantly high values at $100^{\circ} \mathrm{C}$ and $200^{\circ} \mathrm{C}$. Autoxidation of palm oil is 273 protected by its high antioxidant properties consisting of vit E, carotenes etc. and comparatively 274 higher degree of saturation [37]. Similar stability was observed in palm oil over soya oil in s 275 single heating [30] 
276 Contrarily, because of the high degree of unsaturation in groundnut oil it was more oxidized

277 even at room temperature hence a high peroxide value.

\section{$278 \quad 4.0$ Saponification Value}

279 The Table 4.0 below represents the mean saponification values of the oils (Palm, Coconut and 280 Groundnut) after being subjected to different temperatures of heating.

\section{Table 4.0}

282

283 The saponification value of oil is the number of $\mathrm{mg}$ of potassium hydroxide $(\mathrm{KOH})$ required to 284 saponify $1 \mathrm{~g}$ of a fat or oil [38]. High saponification value is an indication that oils are normal 285 triglycerides. The saponification value is also an estimation of the molecular weight of the fat or 286 oil, the higher the molecular weight the smaller is its saponification value because larger 287 molecules have relatively fewer number of carboxylic functional groups per unit mass of the fat. 288 Saponification value also indicates the carbon chain length of the acid present in the oil or fat, 289 the higher the saponification value, the greater is the percentage of the short chain acids present 290 in the glycerides of the oil or fats $[1,39]$. High saponification number is also an indication of high 291 degree of unsaturation in an oil sample.

292 The saponification value of coconut oil was significantly higher than that of groundnut and palm 293 oils, (Table 4) this is possibly because of the higher amount of saturation and shorter chain 294 length (lauric acid (C12:0) and or smaller molecular size which confers the property of having a 295 higher saponification value [40]. Even though groundnut oil has the higher unsaturation than the other oils but because of its high chain length and or molecular weight (mainly composed of 
297 linoleic (C18:2) and arachidic acid (C20:0)) therefore rather has the lowest saponification value.

298 However, the saponification values of the oils were significantly increased after thermal 299 treatment, similar effect was observed by Adewole et al on groundnut oil[41]

\section{Table 5}

305 Unsaponifiable are components of an oily (oil, fat, wax) mixture that fail to form soaps when 306 treated with sodium hydroxide (lye) or potassium hydroxide. Unsaponifiable constituents are an 307 important consideration when selecting oil mixtures for the manufacture of soaps. 308 Unsaponification values were similarly significantly increased across the three thermal 309 treatments and were higher for palm oils as compared to the other oils (Table 5)

\section{Total Phenol content}

311 Screening for phytoconstituents in the oils indicated the presence of steroids, Terpenoids,

312 Cardiac glycosides and carotenoids at all the treated temperatures.

313 Fig 1A, 1B and 1C depicts the total Phenolic capacity of Palm oil (PO) Coconut oil (CO) and 314 groundnut oil (GO)

315 Fig 1A, Phenolic content of Palm oil (PO)

316 Fig 1B Phenolic content of Coconut oil (CO) 
317 Fig1C Phenolic content of Groundnut oil (GO)

318 Phenols contain antioxidant, antimutagenic, and anticancer properties [42]. Flavonoids naturally

319 occurred in polyphenolic compounds and represent one of the most prevalent compounds in 320 vegetables, nuts and fruits $[43]$.

321 There was a significant $(\mathrm{p} \leq 0.001)$ increase in phenol content in palm oil and groundnut oil at 322 higher temperatures (Fig 1A, 1B) and a significant increase at $100^{\circ} \mathrm{C}$ in coconut oil but a 323 significant decrease at $200 \mathrm{C}^{\circ} \mathrm{C}$ (Fig 1C) over a single heating.

324 Repeated heating process have been shown to cause loss of phenolic acids and flavonoids. The 325 degree of loss of phenolic acids in oil after heating was less than that of flavonoids. This may 326 confirm that thermal treatment causes oxidation and polymerization of phenolic compounds. The 327 amount of phenolic compound content is related to their antioxidant activity and may be the 328 main mechanism of protection against diseases related to excessive oxygen radical formation 329 exceeding the antioxidant defense capacity [44]

330 Degradation of natural antioxidants such as phenolic compounds and tocopherol was also 331 observed in virgin olive oils and sunflower oils during domestic frying [45]. Refined and 332 deodorized palm olein, groundnut oils showed a reduction in $\alpha$-tocopherol and $\beta$-carotene levels 333 over repeated heating [46]. In comparison to our finding, in which these compounds did not 334 deteriorate much, may imply that these antioxidants may be stable over short period of single 335 heating but rapidly deteriorate on repeating heating. 


\section{Total antioxidant capacity}

338 Fig 2A, 2B and 2C depicts the total antioxidant capacity of Palm oil (PO) Coconut oil (CO) and 339 groundnut oil (GO)

340 Fig 2A Total antioxidant activity of palm oil (PO)

341 Fig 2B Total antioxidant activity of Coconut oil (CO)

342 Fig 2C Total antioxidant activity of Groundnut oil (GO)

343 Total antioxidant capacity was not significantly changed in palm oil and groundnut oil at all 344 temperature treatment (Fig $2 \mathrm{~A}$ and $2 \mathrm{C}$ ). There was only a significant increase at $200^{\circ} \mathrm{C}$ in 345 coconut oil. (Fig 2B). Antioxidant substances have been shown to accelerate the action of the 346 free radicals by scavenging and detoxification. Phenolics and other natural compounds protect 347 against reactive oxygen species-mediated damage which helps with the avoidance and/or curing 348 of diseases. Antioxidants from, fruits and vegetables are safer as compared to artificial 349 antioxidants such as butylated hydroxytoluene (BHT) known to be carcinogenic [47]. The 350 ingestion of fruits have been associated with reducing aging and mortality from cardiovascular 351 and neurodegenerative diseases [48]. However, Antioxidant activity has been shown to be

352 decreased during heating process observed in in flaxseed hull oil contrary to our finding over a 353 single heating. This implies the oils may still retain their antioxidant property over a single 354 heating/cooking. 
357 Fig 3A, 3B and 3C depicts the free radical scavenging activity of Palm oil (PO) Coconut oil $358 \quad(\mathrm{CO})$ and groundnut oil (GO)

359 Fig 3A DPPH Free Radical Scavenging Activity Palm oil (PO)

Fig 3B DPPH Free Radical Scavenging Activity Coconut oil (CO)

361 Fig 3C DPPH Free Radical Scavenging Activity Ground nut oil (GO)

362 The free radical scavenging activity of the oils was significantly decreased at all temperatures 363 compared to ascorbic acid, but within the oils, temperatures had no significant change, in free 364 radical scavenging activity over a single heating/cooking similar to the observation of Siger et al 365 [44].

366 The DPPH (1,1-diphenyl-2-picrylhydrazyl) radical is used widely to determine the antioxidant 367 activities of plant extracts and foods. The method is based on the reduction of DPPH in methanol 368 solution in the presence of a hydrogen-donating antioxidant, bringing about a color change from 369 purple to yellow, measured at $517 \mathrm{~nm}$. (Fig 3A, 3B and 3C)

370 The absorbance of DPPH from heated oil (Flaxseed hull oil) showed a higher antioxidant activity 371 of $49.74 \%$. This implies heated flaxseed hull oil contains less antioxidant compounds which 372 decreased the DPPH radical scavenging capacity. The scavenging potential of plant constituents 373 have been shown to be related to polyphenolic compounds [44]. The mechanism by which the 374 constituents of flaxseed hull oil, exhibit free radical scavenging activity is still unclear. The 375 antioxidative activity of flaxseed hull oil may be due to the presence of polyphenols [49]. 376 Polyphenols and flavonoid, vitamin E and C are heat labile and degrade even at the time of the 
377 oils extraction processes which involve the use of heat [50]. It was therefore not surprising that

378 measurement of vitamin $\mathrm{E}$ and $\mathrm{C}$ were below detectable limits, and of course vit $\mathrm{C}$ is a water

379 soluble.

\section{Conclusion}

383 There were no significant changes of acid value in groundnut oil, palm oil and coconut oil at

384 higher temperature compared to the room temperature value, hence there was no significant

385 degree of degradation of the oil quality resulting from hydrolysis of triacylglycerols of the oils as

386 a result of heating. The Iodine value which is a measure of the degree of unsaturation in the oils

387 was not significantly changed, therefore these oils are less susceptible to oxidation at high

388 temperatures. Palm oil and coconut oil had low peroxide value at room temperature, no

389 significant change at $100^{\circ} \mathrm{C}$ but a significant increase at $200^{\circ} \mathrm{C}$. Groundnut oil on the other hand

390 had comparatively significant peroxide value at room temperature and much higher values at the

391 higher temperatures. The saponification value of coconut oil was significantly higher than that of

392 groundnut and palm oils possibly due to its comparative higher unsaturation and smaller

393 molecular weight. The phenolic constituents in all the oils were not significantly changed after

394 thermal treatment, hence the total antioxidant and free radical scavenging activities were

395 significantly retained. The overall quality of the oils was not significantly changed in just one

396 heating. This implies these vegetable oils may still retain their antidiabetic properties after a

397 single thermal treatment in food processing/cooking. 


\author{
Abbreviations \\ CO: Coconut oil; GO: Groundnut oil; PO: Palm oil.
}

\title{
DECLARATION
}

\section{Ethics approval and consent to participate}

The protocol for this study was approved by the Health Service Ethics Committee, School of Medicine and Dentistry, Kwame Nkrumah University of Science and Technology Kumasi Department of Health Service Publication No 83-23, revised 1985

Consent for publication

All authors have given their consent for the publication of this manuscript

Availability of data and materials

All data generated or analysed during this study are included in this published article [and its supplementary information files

\section{Competing interests}

The authors declare that they have no competing interests.

\section{Funding}

No funding

\section{Authors' contributions}

RAN developed the concept and design of the study and coordinated the data collection and prepared the manuscript for publication. JB supervised the project assisted in critically reviewing of the manuscript. EOA and DB generated the data for the work and assisted in analysis and interpretation of the data. SK participated in analysis and interpretation of the data. All authors read and approved the final manuscript.

\section{Acknowledgement}

${ }^{1}$ Department of Molecular Medicine, School of Medical Science, Kwame Nkrumah University of Science and Technology (KNUST), Kumasi, Ghana.

${ }^{2}$ Kwame Nkrumah University of Science and Technology Kumasi Ghana Department of Food and Biotechnology

\section{References}

1. Alajtal AI, Sherami FE, Elbagermi MA. Acid, Peroxide, Ester and Saponification Values for Some Vegetable Oils Before and After Frying. AASCIT Journal of Materials. 2018; 4 (2): 43-47.

2. Lacatusu I, Niculae G, Badea N, Stan R, Popa O, Oprea O, Meghea A. Design of soft lipid nanocarriers based on bioactive vegetable oils with multiple health benefits. Chemical Engineering Journal. 2014;15(246):311-21. [Cited 26 June 2019]. Available from:https://www.sciencedirect.com/science/article/pii/S1385894714001880

3. Vaidya UV, Hegde VM, Bhave SA, Pandit AN. Vegetable oil fortified feeds in the nutrition of very low birthweight babies. Indian pediatrics. 1992;29(12):1519-27. [Cited 26 June 2019]. Available from:https://europepmc.org/abstract/med/1345325 
4. Aluyor EO, Ori-Jesu M. The use of antioxidants in vegetable oils-A

5. review. African Journal of Biotechnology. 2008;7(25). [Cited 26 June 2019]. Available from:https://www.ajol.info/index.php/ajb/article/view/59677

6. Innes $\mathrm{J} \mathrm{K}$ and Calder PC. Omega-6 fatty acids and inflammation Prostaglandins, Leukotrienes and Essential Fatty Acids 2018; 132, 41-48

7. Hansson GK, Robertson AK, Soderberg-Naucler C. Inflammation and atherosclerosis. Annu Rev Pathol. 2006; 1:297-329.

8. Libby P, Ridker PM, Maseri A. Inflammation and Atherosclerosis. Circulation. 2002;105(9):1135-43.

9. Lemaitre RN . McKnight B, Sotoodehnia N, Fretts AM. Qureshi WT. Circulating Very Long-Chain Saturated Fatty Acids and Heart Failure: The Cardiovascular Health Study https://doi.org/10.1161/ JAHA.118.010019Journal of the American Heart Association. 2018;7: 21

10. Trevisan M, Krogh V, Freudenheim J, Blake A, Muti P, Panico S, Farinaro E, Mancini M, Menotti A, Ricci G. Consumption of olive oil, butter, and vegetable oils and coronary heart disease risk factors. The Research Group ATS-RF2 of the Italian National Research Council. JAMA. 1990; 2;263(5):688-92. Erratum in: JAMA 1990;;263(13):1768. PMID: 2296124

11. Ngala et al 2015 Ngala1 RA, Ampong I, Sakyi SA and Anto EO. Effect of dietary vegetable oil consumption on blood glucose levels, lipid profile and weight in diabetic mice: an experimental case-control study. BMC Nutrition (2016) 2:28

12. Choo YM . Palm oil carotenoids: Food and Nutrition Bulletin, 1994; 15(2) The United Nations University.

13. Nagendra B, Unnithan UR, Choo YM. Characteristics of Red Palm Oil, a Carotene- and Vitamin E-Rich Refined Oil for Food Uses Food and Nutrition Bulletin. (2000;21(2):189-194 DOI: 10.1177/156482650002100213

14. Ng MH, Choo YM. Improved Method for the Qualitative Analyses of Palm Oil Carotenes Using UPLC. J Chromatogr Sci. 2016; 54(4):633-8. doi: 10.1093/chromsci/bmv241. Epub 2016 Mar 2. PMID: 26941414; PMCID: PMC4885407.

15. Nevin KG, Rajamohan T. Beneficial effects of virgin coconut oil on lipid parameters and in vitro LDL oxidation. Clin Biochem. 2004; 37(9):830-5. doi: 10.1016/j.clinbiochem.2004.04.010. PMID: 15329324

16. L iu X, Jin Q, Liu Y, Huang J, Wang X, Mao W, Wang S. Changes in Volatile Compounds of Peanut Oil during the Roasting Process for Production of Aromatic Roasted Peanut Oil. Food Science. 2011;76(3)

17. Anyasor GN, Ogunwenmo KO, Oyelana O. Chemical Analyses of Groundnut (Arachis hypogaea ) Oil Pakistan Journal of Nutrition. 2009;8(3) DOI: 10.3923/pjn.2009.269.272

18. Chen Y, Yin M, Cao X, Hu G, \& Xiao M. Pro- and Anti-inflammatory Effects of High Cholesterol Diet on Aged Brain. Aging and disease. 2018; 9(3), 374-390. https://doi.org/10.14336/AD.2017.0706

19. Chun-Yi N, Xin-Fang L, Norliana M,Siti KA,Yusof K, Kamsiah J. Heated vegetable oils and cardiovascular disease risk factors Vascular Pharmacology. 2014; 61, (1):1-9

20. AOAC. (1990). Official methods of analysis of the AOAC, 15th ed. Methods 932.06, 925.09, 985.29, 923.03. Association of official analytical chemists. Arlington, VA, USA. 
21. Gorinstein S, Cvikrova M, Machackova I, Haruenkit R, Park YS, Jung ST, Yamamoto K Leticia Martinez Ayala A, Katrich E, \& Trakhtenberg S. (2004). Characterization of antioxidant compounds in Jaffa sweeties and white grapefruits. Food Chemistry, 84(4), 503-510. http://dx.doi.org/10.1016/S0308-8146(03)00127-4.

22. Umamaheswari M, Chatterjee TK. In vitro antioxidant activities of the fractions of Coccinnia grandis L. leaf extract. Afr J Trad Complement Altern Med. 2007 Oct;5(1):61-73. [PMC free article] [PubMed] [Google Scholar

23. Sakat SS, Juvekar AR, Gambhire MN. In vitro antioxidant and anti-inflammatory activity of methanol extract of oxalis corniculata linn, International Journal of Pharmacy and Pharmaceutical Sciences, (2010); 2 (1), 146-155

24. Vaskova H, Buckova M. Thermal Degradation of Vegetable Oils: Spectroscopic Measurement and Analysis 25th DAAAM International Symposium on Intelligent Manufacturing and Automation, DAAAM 2014 Procedia Engineering 100630 - 635

25. Ngassapa FN, Nyandoro $S$ and Mwaisaka TR. Effects of temperature on the physicochemical properties of traditionally processed vegetable oils and their blends Tanz. J. Sci. 2012; 38(3), 166-176

26. Awney HA. The effects of Bifidobacteria on the lipid profile and oxidative stress biomarkers of male rats fed thermally oxidized soybean oil Biomarkers, (2011; 16 (5): 445-452

27. Giua L, Blasi F, Simonetti MS, Cossignani L. Oxidative modifications of conjugated and unconjugated linoleic acid during heating. Food Chem. 2013;140(4):680-5. doi: 10.1016/j.foodchem.2012.09.067. Epub 2012 Sep 28. PMID: 23692753.

28. Malvis A, Peter Š , Tibor D, Sládková A, Aleš Ház, Jablonský M, Sekretár S, Schmidt S, František K, Zuzana B, Gassan H, Igor Š. "Determination of the Thermal Oxidation Stability and the Kinetic Parameters of Commercial Extra Virgin Olive Oils from Different Varieties", Journal of Chemistry, 2019; 8 . https://doi.org/10.1155/2019/4567973

29. Adam SK, Sulaiman NA, Mat Top AG, Jaarin K. Heating reduces vitamin E content in palm and soy oils Malays J Biochem Mol Biol. 2007; 15 (2): 76-79

30. Jaarin K and Kamisah Y Repeated heated vegetable oils and lipid peroxidation, Angel Catala, IntechOpen (2012). DOI:10.5772/46076, (https://www.intecopen.com/chapter/38471

31. Gharby S, Harhar H, Matthäus B, Bouzoubaa Z. and Charrouf Z. The chemical parameters and oxidative resistance to heat treatment of refined and extra virgin Moroccan Picholine olive oil. Journal of Taibah University for Science. 2016;10: 100.

32. Kaleem1 A, Aziz S, Iqtedar M, Abdullah R, Aftab M, Rashid F, Shakoori FR and S Naz S. Investigating changes and effect of peroxide values in cooking oils subject to light and heat. FUUAST J. BIOL. 2015; 5(2):191-196

33. Codex Alimentarius 2006: and Codex Standard for named Vegetable oils: Codex-Stand 210

34. Araújo JMA. Food Chemistry: Theory and Practice. UFV. 2004; 416 
35. Falade $\mathrm{AO}$ and Oboh G.Thermal Oxidation Induces Lipid Peroxidation and Changes in the Physicochemical Properties and $\beta$-Carotene Content of Arachis Oil International Journal of Food Science Volume 2015 |Article ID 806524 | https://doi.org/10.1155/2015/806524

36. Moreno JJ, Mitjavila MT. The degree of unsaturation of dietary fatty acids and the development of atherosclerosis (review). J Nutr Biochem. 2003;14(4):182-95. doi: 10.1016/s0955-2863(02)00294-2. PMID: 12770642.

37. Balasundram N, Ai TY, Sambanthamurthi R, Sundram K, Samman S. Antioxidant properties of palm fruit extracts. Asia Pac J Clin Nutr. 2005;14(4):319-24. PMID: 16326638.

38. Carrero Á. Pérez A .5 - Advances in biodiesel quality control, characterisation and standards development, Advances in Biodiesel Production,Processes and Technologies, Woodhead Publishing Series in Energy. 2012. 91-130

39. Odoom W and Eduse VO. Evaluation of Saponification value, Iodine value and Insoluble impurities in Coconut Oils from Jomoro District in the Western Region of Ghana Asian Journal of Agriculture and Food Sciences. 2015, 3(5) 494-499

40. Abayeh OJ, Aina EA and Okuonghae CO. Oil content and oil quality characteristics of some Nigerian oil seeds. J. Pure and Applied Sci. 1998;1: 17-23.

41. Odewole M, Oyeniyi S, Adesoye E. (2016). Effect of process conditions on the physicochemical properties of groundnut oil extracted with a Vertical Screw Jack. Annals. Food Science and Technology. 17. 492-496.

42. Ahmad N, Mukhtar H. Green tea polyphenols and cancer: biological mechanisms and practical implications. Nutr Rev. 1999 Mar;57(3):78-83.

43. Hertog MGL, Hollman PCH, Van de Putte B. Content of potentially anticarcinogenic flavonoids of tea infusion wines and fruit juices. J Agric Food Chem. 1993 Aug;41(8):1242-1246.

44. Siger A, Nogala-Kalucka M, \& Lampart-Szczapa E. (2008). The content and antioxidant activity of phenolic compounds in cold pressed plant oils. Journal of Food Lipids, 15(2), 137-149.

45. Andrikopoulos NK, Dedoussis GV, Falirea A, Kalogeropoulos N, Halzinikola HS. Deterioration of natural antioxidants species of vegetable edible oils during the domestic deep frying and pan frying of potatoes. Int J Food Sci Nutr:2002; 53: 531-361

46. Evuen UF, Apiamu A, Ugbeni OC. Toxicological potential of repeated frying on antioxidant status of vegetable oils. Int J Eng Res Tec 2013

47. Anagnostopoulou MA, Kefalas P, Papageorgiou VP Radical scavenging activity of various extracts and fractions of sweet orange peel (Citrus sinensis) Food Chem. 2006 Jan;94(1):19-25.

48. Verzelloni E, Tagliazucchi D, Conte A. Relationship between the antioxidant properties and the phenolic and flavonoid content in traditional balsamic vinegar. Food Chem. 2007;105(2):564-571. 
49. Hao M, \& Beta T. Qualitative and quantitative analysis of the major phenolic compounds as antioxidants in barley and flaxseed hulls using HPLC/MS/MS. Journal of the Science of Food and Agriculture, . (2012); 92(10), 2062-2068. http://dx.doi.org/10.1002/jsfa.5582. PMid:22278383.

50. Özcan MM, Juhaimi FA, Uslu N. The effect of heat treatment on phenolic compounds and fatty acid composition of Brazilian nut and hazelnut. J Food Sci Technol. 2018 Jan;55(1):376-380. doi: 10.1007/s13197-017-2947-3. Epub 2017 Nov 8. PMID: 29358830; PMCID: PMC5756223 
Figures

A

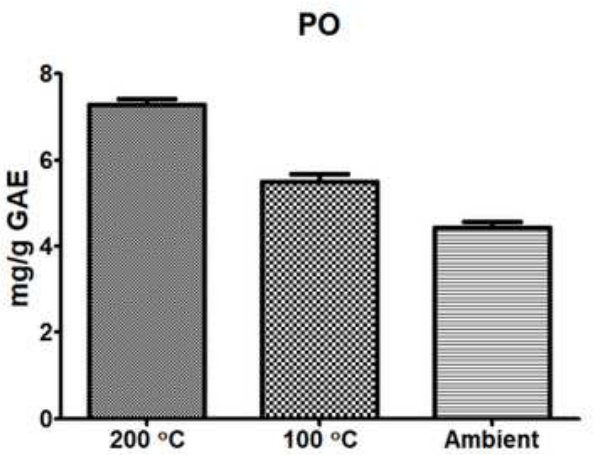

$P$ value is $<0.0001$ hence means are statistically different

B

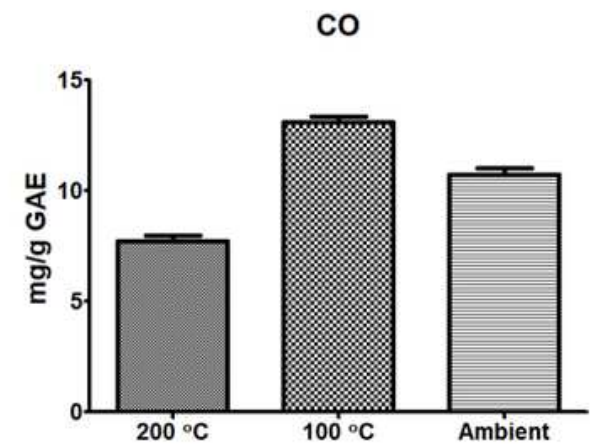

$\mathrm{P}$ value is 0.0001 hence means are statistically different

C

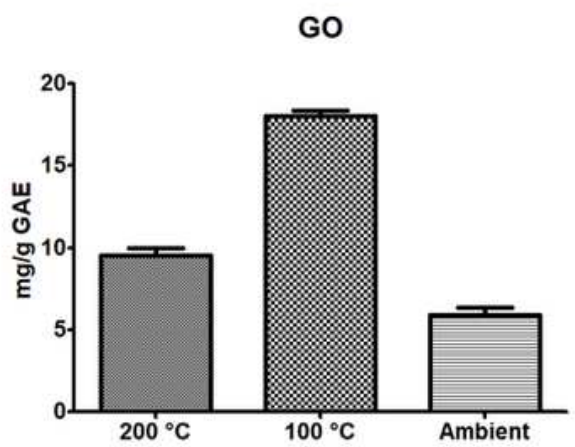

$\mathrm{P}$ value is $<0.0001$ hence means are statistically different

\section{Figure 1}

$A$ : The effect of thermal treatment on the Phenolic content of Palm oil

$B$ : The effect of thermal treatment on the Phenolic content of Coconut oil 
A PO

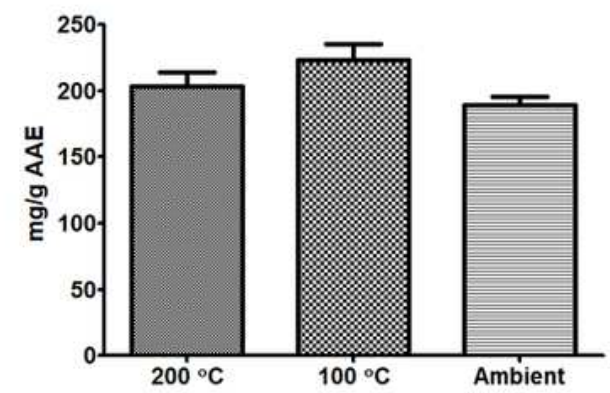

$P$ value is 0.1343 hence means are not statistically different since p value is greater than 0.05

B

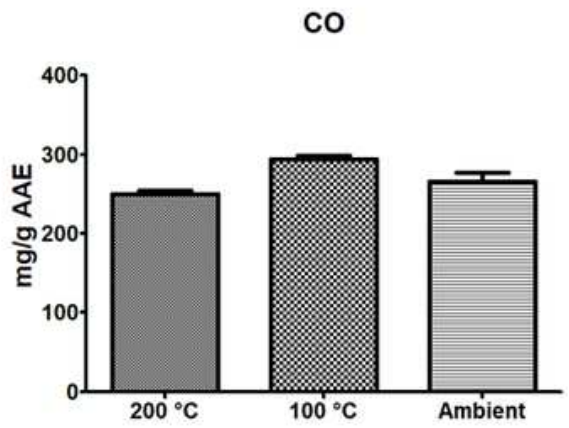

$P$ value is 0.0137 hence values are statistically different since $p$ value is less than 0.05

C

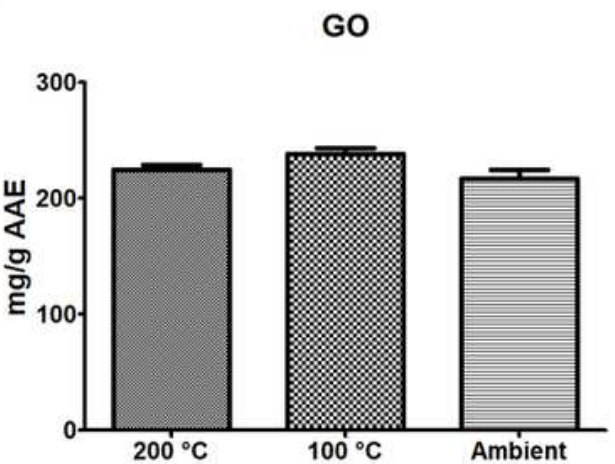

$P$ value is 0.1087 hence means are not statistically different since $P$ value is not less than 0.05

\section{Figure 2}

A: The effect of thermal treatment on the Antioxidant capacity of Palm oil B: The effect of thermal treatment on the Antioxidant capacity of Coconut oil 
A

DPPH Free radical scavenging of PO

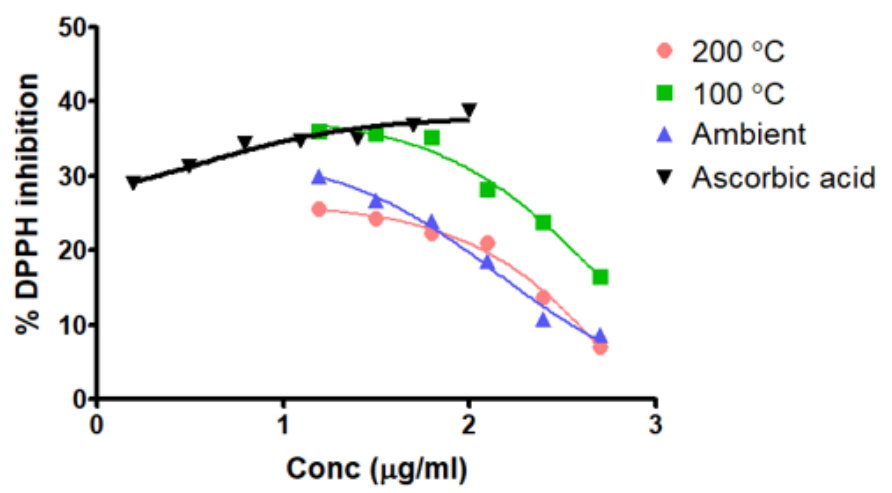

\begin{tabular}{|l|l|}
\hline Sample & $\mathrm{IC}_{50}(\mu \mathrm{g} / \mathrm{mL})$ \\
\hline $\mathrm{PO}($ Ambient $)$ & 139.6 \\
\hline $\mathrm{PO}\left(100^{\circ} \mathrm{C}\right)$ & 508.3 \\
\hline $\mathrm{PO}\left(200^{\circ} \mathrm{C}\right)$ & 909.9 \\
\hline $\mathrm{CO}($ Ambient $)$ & 6074 \\
\hline $\mathrm{CO}\left(100^{\circ} \mathrm{C}\right)$ & 334.6 \\
\hline $\mathrm{CO}\left(200^{\circ} \mathrm{C}\right)$ & 2102 \\
\hline $\mathrm{GO}($ Ambient $)$ & 419.4 \\
\hline $\mathrm{GO}\left(100^{\circ} \mathrm{C}\right)$ & 2453 \\
\hline GO $\left(200^{\circ} \mathrm{C}\right)$ & 28.72 \\
\hline Ascorbic acid & 3.505 \\
\hline
\end{tabular}

B

DPPH Free radical scavenging activity of CO

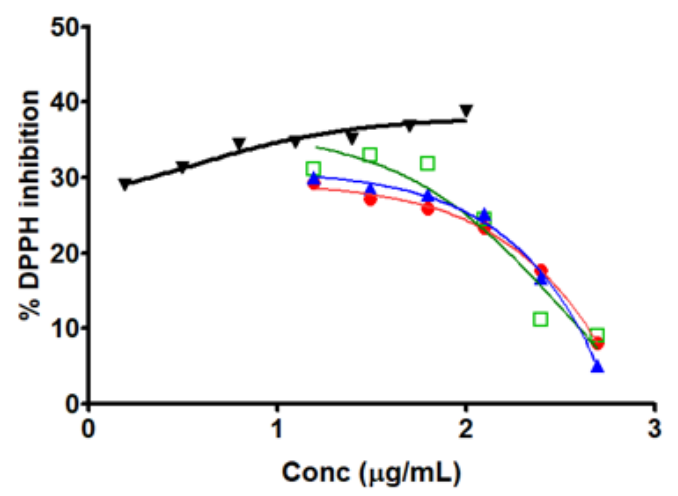

- $200^{\circ} \mathrm{C}$

ㅁ $100^{\circ} \mathrm{C}$

$\triangle$ Ambient

- Ascorbic acid

C

DPPH Free radical scavenging activity of GO

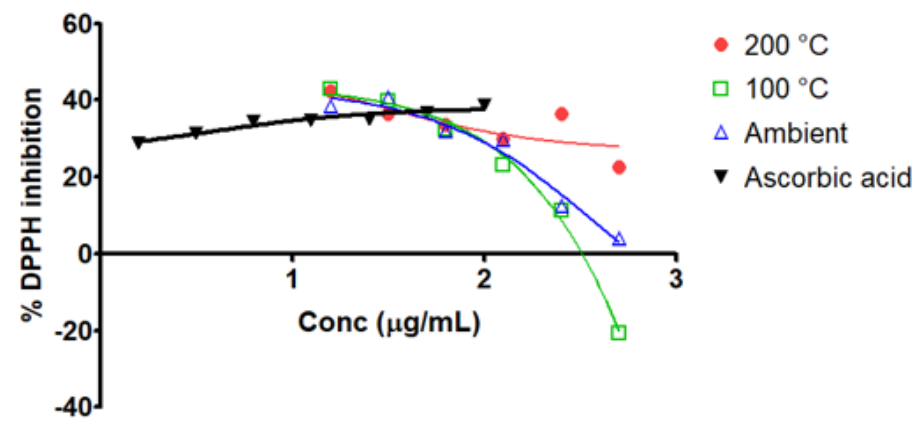

\section{Figure 3}

A: The effect of thermal treatment on the Free Radical Scavenging Activity of Palm oil

B: The effect of thermal treatment on the Free Radical Scavenging Activity of Coconut oil 
C: The effect of thermal treatment on the Free Radical Scavenging Activity of Groundnut oil

\section{Supplementary Files}

This is a list of supplementary files associated with this preprint. Click to download.

- Data.docx

- Data1.docx

- Data3.xlsx 